\title{
破裂脳動脈瘤重症例の治療
}

\author{
藤井 聡, 藤津 和彦, 田中直樹, 高梨 吉 裕 \\ 持松泰彦, 枚田一広, 西村敏, 鈴木範行 \\ 篠 永正道, 桑原 武夫
}

\section{Management of Severe Cases with Aneurysmal SAH}

Satoshi FujII, M.D., Kazuhiko Fujitsu, M.D., Naoki TAnaka, M.D., Yoshihiro TaKanashi, M.D., Yasuhiko Mochimatsu, M.D., Kazuhiro Hirata, M.D., Satoshi Nishimura, M.D., Noriyuki Suzuki, M.D., Masamichi Shinonaga, M.D., and Takeo Kuwabara, M.D.

Department of Neurosurgery, Yokohama City University School of Medicine, Yokohama, Japan

Summary : Out of 380 patients who underwent CT scanning on the day of aneurysmal rupture, 67 were classified as Hunt and Kosnik grade IV.V several hours after the initial SAH when neurologic. al status was most stable.

Precise information was available from the initial ictus in these 67 patients, about the episodes suggestive of rebleeding i.e., sudden deterioration of consciousness level with or without headache, nausea, and vomiting. The most frequent factors causative of the poor grade in these patients were series-forming multiple bleeds in a short period immediately after the first ictus. These too early rebleeding episodes appeared hardly preventable even by ultra-early surgery. The most important regimen seemed to be mild induced hypotention and deep sedation upon transfer, and preoperative examinations.

As for CT evaluation the maximus two sites of cisternal high density area were chosen and summed up by CT number; this is designated as the SAH score. Neither intracerebral hematoma (ICH) nor intraventricular hemorrhage (IVH) was included in the CT number sum up for this SAH score. Almost all these 67 patients demonstrated ICH and/or IVH in addition to SAH of varied SAH scores. The prognosis in these patients were generally poor, and only three patients had good outcome after early operation. Although the concomitant ICHs or IVHs were large, it is noteworthy that SAH scores were relatively low in these patients with good outcome.

The surgical indication for poor grade patients with ruptured aneurysm is quite limited. However, a small number of patients, who have large ICH and/or IVH not associated with massive SAH, may be possible candidates for ultra-early aneurysmal surgery with hematoma removal.

Key words :

- ruptured aneurysm

- SAH score

- ICH

- IVH

- rebleeding 


\section{はじめに}

近年，破裂脳動脈瘤軽症および中等症においては，積極 的に早期手術がすすめられている1). しかしながら，破裂 早期から重症となる症例の治療成績は惨憺たるものであり, このような症例の成績をいかに向上させるかが，今後の問 題と考えられる. 我々の経験した重症例の原因を分析し今 後の治療方針の検討を行った.

\section{対象}

過去12年間に発症直後からの経過を詳細に知りえ，かつ 発症当日に入院し，CT-scan を施行した症例 380 例から， 発症数時間以上経過し神経学的に安定したと思われる時点 での意識レベルが Japan coma scale (JCS) 100以上の67例 を対象とした．本来の Hunt and Kosnik grade IV は JCS 30以上に相当すると思われるが，本論文ではより重症例に 限定するため, JCS 100 以上とした。これらの症例の内訳 は男女比29：38とやや女性に多く, 動脈瘤の発生部位は中 大脳動脈瘤に多く認められた. しかし，脳血管撮影まで施 行しえた症例が30例と全体の半数以下に限られるため, CT上の血腫部位から動脈瘤の部位を推定した症例も含ま れている.

\section{方法}

どのような経過で重症例が発生するか知るため, 詳細な 病歴の聴取と来院後の神経学的徴候の推移を調査した. ま た, 再出血の時期は全380例の症例について調査した.

CT-scan によるクモ膜下出血の程度の分類は, 種々なさ れているが2), 我々は basal cistern 全体の出血の量が表現 でき，かつ局所的に強い出血をも評価できるものとして， 以下の方法を用いている3)。 すなわち，CT-scan 上 $\mathrm{SAH}$ の程度の最も強い 2 つの cistern を選んで, その CT 值を 合算し, SAH score とする方法である. 脳内出血 $(\mathrm{ICH})$ と脳室内出血 (IVH) は SAH score にいれず, 別個に検討 した.

予後は退院時の状態により以下の 5 段階に評価した. spasm の臨床症候をほとんど示さなかったもの no spasm $(\mathrm{N})$, 一過性の神経症候 (意識障害の進行を含む)だけで, ほぼ完全に回復したもの $\operatorname{good} \operatorname{recovery}(\mathrm{G})$, 片麻瘏や失 語症などの部分的な神経脱落症候をのこしたもの fair recovery $(\mathrm{F})$ ，ねたきりまたは植物的状態となったもの poor recovery $(\mathrm{P})$, 死亡例 $\operatorname{dead}(\mathrm{D})$ とした.

\section{結 果}

\section{1. 重症例にいたる経過}

全380例の発症14日までの再出血の調査を Fig. 1 に示す

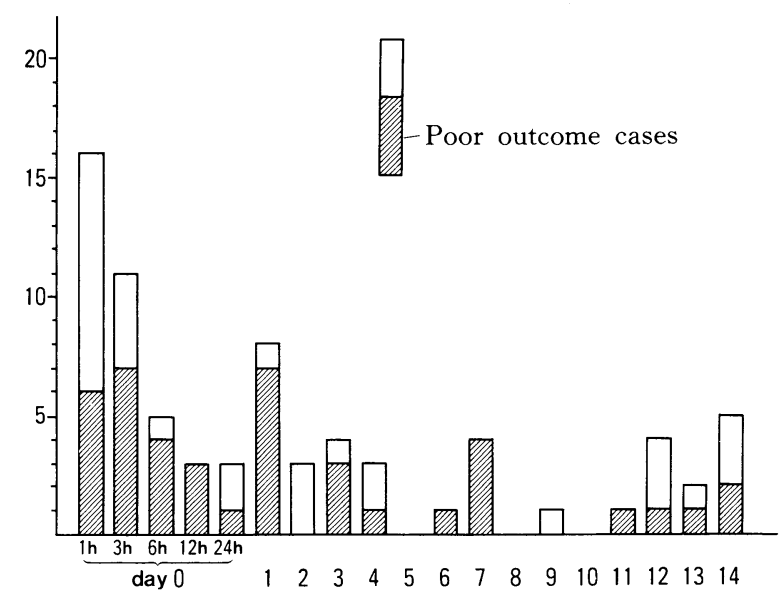

Fig. 1 Rebleeding within 14 days of SAH.

Table 1 Outcome of grade $(\mathrm{I} \sim \mathrm{II})$ patients not associated with ICH or IVH

\begin{tabular}{|c|c|c|c|c|c|}
\hline $\begin{array}{l}\text { SAH } \\
\text { score }\end{array}$ & $N$ & G & $\mathrm{F}$ & $\mathrm{P}$ & $\mathrm{D}$ \\
\hline 1 & $64(86 \%)$ & $9(12 \%)$ & $1(1 \%)$ & & \\
\hline 2 & $52(56 \%)$ & $31(33 \%)$ & $6(6 \%)$ & $3(3 \%)$ & $1(1 \%)$ \\
\hline 3 & & $13(37 \%)$ & $8(23 \%)$ & $4(11 \%)$ & $10(29 \%)$ \\
\hline 4 & & & $2(10 \%)$ & $6(30 \%)$ & $12(60 \%)$ \\
\hline
\end{tabular}

There is a good correlation between the SAH scores and the outcomes. N; no spasm, G; good recovery, F; fair recovery, P; poor recovery, D; dead

が, 再出血74例中, 6 時間以内に32回の再出血が生じてい た. 重症例にいたるまでの経過で再出血によると思われる 意識レベルの低下のみられた症例を調査すると, シリーズ を形成して再出血を生じたものが多かった.

\section{CT 所見と予後}

まず，対照として，我々の SAH scoreにより, Hunt and Kosnik の grade I-IIIで血腫を合併しない症例を分類 し, 予後と対比した結果を, Table 1 に示す. SAH score と予後が相関することが明らかであった，次に，重症例の SAH score と予後の関係を Table 2 に示す. SAH score の 分布は, Grade III までの症例よりややscore が高い傾向を 示した. しかし SAH score と予後の関係みると, 予後不 良例が95\%であるため両者の関係は明らかでなかった。

Table 2の（）で示すごとく, 重症例はクモ膜下出血単 独でなく血腫合併例が71\%にみられた，併存したものを含 めて, 脳内血腫33例, 脳室内出血 27 例, 硬膜下出血 2 例を 合併していた. 対比として, Hunt and Kosnik の grade I 一 IIIIの血腫合併例を, Table 3に示すが, これらの症例で はSAH scoreにより, 予後が決定されていた。 


\section{3. 予後良好例の CT 所見}

Table 2に示したごとく，重症例の中で予後良好であっ た症例は 3 例のみであったが，その CT 所見を Fig. 2 に示 す、いずれも中大脳動脈瘤例であり，また，いずれも脳内 血腫が poor grade の主因であり, SAH score は $1 〜 2$ と 低かった. 早期に aneurysmal neck clipping と血腫除去術 を施行し，良好な結果を得た。

\section{4. 予後不良例の CT 所見}

予後不良となった代表例の CT 所見を Fig. 3 に示すと, 左端は massive な SAH の症例であり, 中央は castを形 成したIVH の症例であった．右端は脳内血腫を合併した 中大脳動脈瘤例ではあるが, 血腫は前頭葉と側頭葉の両者 にわたり発育し，しかも SAH score も高い症例であった.

\section{考案}

今回の調査の結果に示されるように，脳動脈瘤破裂早期 から JCS 100 以上となる症例の予後は一般に極めて不良で ある. 予後不良の原因を検討した結果, 以下の 2 点につい ては治療方針の工夫によって, 予後の改善が期待できると 思われた。

近年, 発症後超早期の再破裂の頻度が極めて高いことが 認識されている。したがって angiography などの侵襲的 な検査は発症 $5 \sim 6$ 時間以内は避けるという方針をとって いる施設も多く見られている ${ }^{4)}$. 病歴の詳細な聴取と前医 からの報告を参考にすると，JCS 100以上の状態に至るま でには，再破裂がシリーズを形成している場合が，多いこ とが明らかになった，再破裂により予後が，極めて不良と
Table 2 Outcome of poor grade patients

\begin{tabular}{|c|c|c|c|c|c|}
\hline $\begin{array}{l}\mathrm{SAH} \\
\text { score }\end{array}$ & $\mathrm{N}$ & $\mathrm{G}$ & $\mathrm{F}$ & $\mathrm{P}$ & $\mathrm{D}$ \\
\hline$\frac{1}{(\mathrm{ICH} . \mathrm{IVH}(+))}$ & & $\begin{array}{c}2 \\
(2)\end{array}$ & $\begin{array}{c}1 \\
(1)\end{array}$ & $\begin{array}{c}1 \\
(1)\end{array}$ & $\begin{array}{c}15 \\
(15)\end{array}$ \\
\hline $\begin{array}{l}2 \\
(\mathrm{ICH} . \mathrm{IVH}(+))\end{array}$ & & $\begin{array}{c}1 \\
(1)\end{array}$ & $\begin{array}{c}1 \\
(1)\end{array}$ & $\begin{array}{c}2 \\
(1)\end{array}$ & $\begin{array}{c}5 \\
(3)\end{array}$ \\
\hline $\begin{array}{l}3 \\
(\mathrm{ICH} . \mathrm{IVH}(+))\end{array}$ & & & & $\begin{array}{c}4 \\
(1)\end{array}$ & $\begin{array}{c}4 \\
(2)\end{array}$ \\
\hline $\begin{array}{l}4 \\
(\mathrm{ICH} . \mathrm{IVH}(+))\end{array}$ & & & & $\begin{array}{c}7 \\
(4)\end{array}$ & $\begin{array}{c}24 \\
(16)\end{array}$ \\
\hline
\end{tabular}

Most of those patients show high SAH scores and coexistent ICH and/or IVH.

Only three patients with low scores had good outcomes.

Table 3 Outcome of grade $(\mathrm{I} \sim \mathrm{III})$ patients associated with small ICH and/or IVH

\begin{tabular}{|c|c|c|c|c|c|}
\hline $\begin{array}{l}\text { SAH } \\
\text { score }\end{array}$ & $\mathrm{N}$ & G & $\mathrm{F}$ & $\mathrm{P}$ & D \\
\hline 1 & $17(89 \%)$ & $2(11 \%)$ & & & \\
\hline 2 & $7(39 \%)$ & $10(56 \%)$ & $1(6 \%)$ & & \\
\hline 3 & & & & & 3 \\
\hline 4 & & & & 2 & 1 \\
\hline
\end{tabular}

The SAH score is the most reliable indicator of the outcome of these patients.

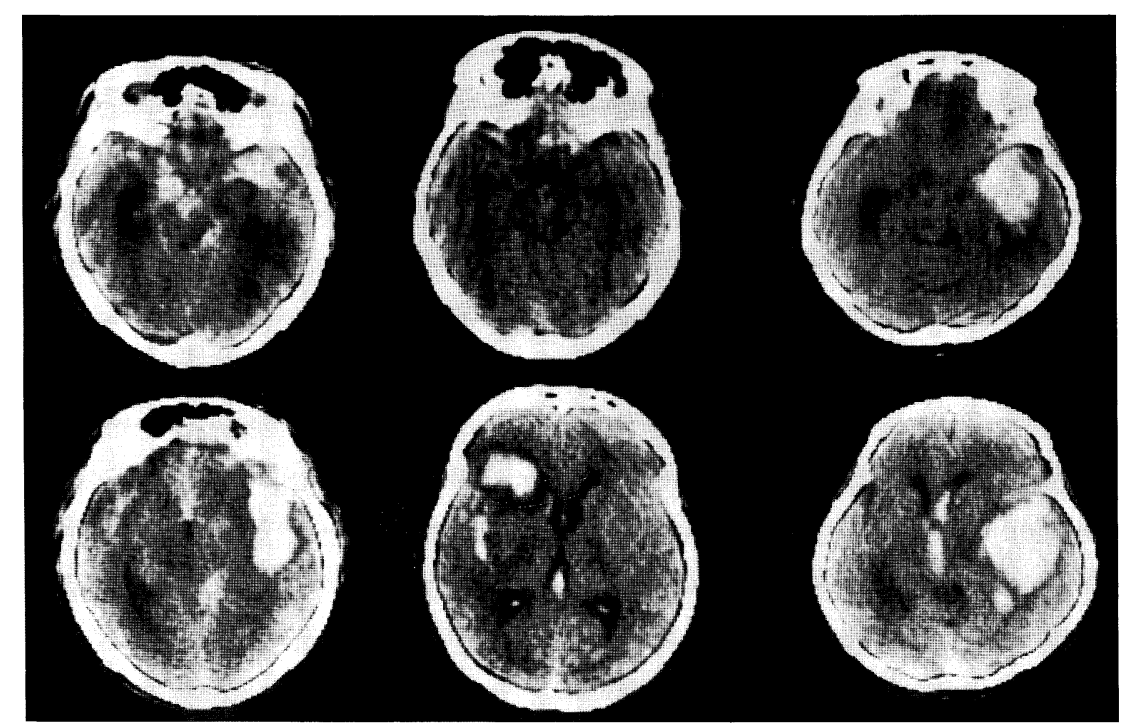

Fig. 2 Three patients with good outcome. CTs in a single patient are paired in tandem. 


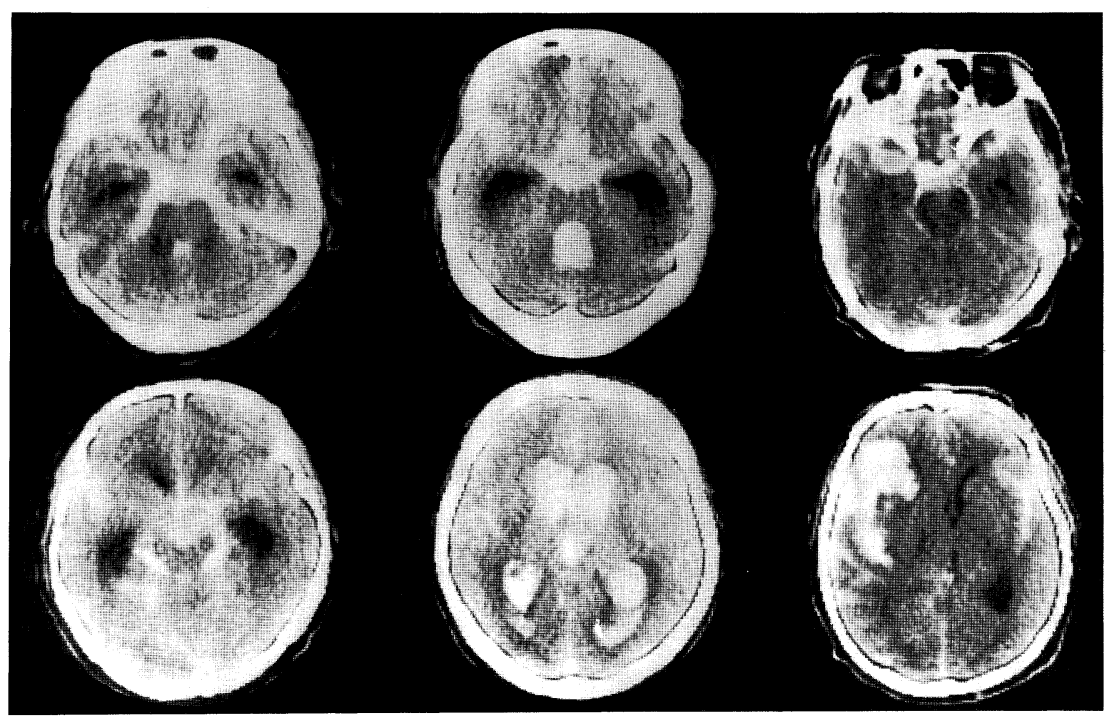

Fig. 3 Three patients with poor outcome. CTs in a single patient are paired in tandem.

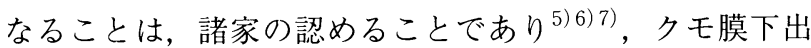
血の早期診断と同時に，十分な sedation と血圧の control を行うことが重要と思われた。ささらに，脳神経外科施設に 搬送するまでの管理について，十分な啓蒙も必要と思われ た.

今回調査の症例中には，わずか 3 例のみではあるが手術 後予後良好となった症例がみられている．良好な予後を期 待できる症例を，いつ，いかなる方法で手術適応として選 択するかが第二の問題である.CT 所見についての検討で は，Hunt and Kosnik の grade III までの症例では，SAH score と予後がよく相関していたが，重症例での相関は明 確でなかった。しかしながら予後良好例は SAH score の 低い症例に限られていた。近年，破裂脳動脈瘤における出 血後早期の意識障害の原因は，脳幹機能の虚脱と説明され ている ${ }^{8)}$. primary brain damage ではなく, massiveな脳 内血腫が意識障害の主因であると判定するには，BSR な どのより他覚的な検索方法の導入が必要となってくるであ ろう ${ }^{9)}$.

破裂脳動脈瘤に脳内血腫を合併する頻度は10～30\%とさ れているが，今回調査の重症例では71\%は脳内出血または 脳室内出血を合併していた。一般に脳内出血の合併は再出 血例に多いとされてはいる年が，我々の症例でもシリー ズを形成して出血を繰り返し大血腫を形成した例が多くみ られた．従来，脳内血腫を合併する機序として，初回出血 後クモ膜下腔に線維性癒着が生じるためと説明されていた 10) 11)。しかし，今回我々の調査ではクモ膜下出血を繰り 返しクモ膜下腔が出血で充満されたのち，最後に大きな脳 内出血を形成するという機序も示唆された.
一般に予後不良となる血腫径の下限は $4 \sim 5 \mathrm{~cm}$ とされ ている ${ }^{10)}{ }^{12)}$ が, SAH scoreの低い症例では, 大血腫形成 例であっても積極的に手術を行う価値のあるものと思われ た.

\section{結語}

1. 発症早期より Japan coma scale 100 以上となる症例の 予後は不良である.

2．重症例にいたるまでに，早期に再破裂を生じている例 が多く，初期の管理が重要である.

3. 血腫形成例が大部分であるが，SAH score の低い例 に早期手術を行い予後良好となる症例がある。

\section{文献}

1) Mizukami M, Kawase T, Usami T, et al: Prevention of vasospasm by early operation with removal of subarachnoid blood. Neurosurgery 10: 301-307, 1982

2) Fisher CM, Kistler JP, Davis JM: Relation of cerebral vasospasm to subarachnoid hemorrhage visualized by computerized tomographic scanning. Neurosurgery $6: 1-9,1980$

3）藤津和彦, 藤井 聡, 山滝 昭, ほか：クモ膜下出血 Grading の再評価一SAH score と Spasm risk一. 第14回脳 卒中の外科研究会講演集, $1985, \mathrm{pp}$ 71-74

4）伊東正太郎，郭 隆璨，江守 巧，ほか：脳血管撮影中の 破裂脳動脈瘤再破裂の危険性. 脳神経外科 13: 399-407, 1985

5）青柳訓夫，早川 勲，竹村信彦，ほか：破裂脳動脈瘤223例 の解析, 特に再発予防の観点から. 脳神経外科 11: 63-71, 1983

6）長澤史郎，田代 弦，米川泰弘，ほか：破裂中大脳動脈瘤 53例の検討．脳神経外科 13: 983-989, 1985

7）安井信之，鈴木明文，大田英則，ほか：破裂脳動脈瘤急性 期の治療と問題点. Neurol Med Chir (Tokyo) 27: 1158- 
1166,1987

8）片岡和夫，種子田護：低血圧を伴う急性期破裂脳動脈瘤. Neurol Med Chir (Tokyo) 23: 203-210, 1983

9）河村弘庸, 天野恵市, 谷川達也, ほか：急性期重症脳障害 患者の予後判定 聴性脳幹反応 $(\mathrm{ABR})$ と瞬目反射 $(\mathrm{BR})$ によ る評価. 脳神経外科 13: 1077-1085, 1985

10）川村伸悟，鈴木明文，佐山一郎，ほか：脳動脈瘤破裂に伴 う脳内血腫の臨床的意義. Neurol Med Chir (Tokyo) 27:
1158-1166, 1987

11) Crompton MR: Intracerebral hematoma complicating ruptured cerebral berry aneurysm. J Neurol Neurosurg Psychiatry 25: 378-386, 1962

12）猪森茂雄，金 一宇，上田慎介，ほか：脳内血腫を伴った 破裂中大脳動脈瘤, CT 像の特徵と転帰について. Neurol Med Chir (Tokyo) 24: 573-579, 1984 